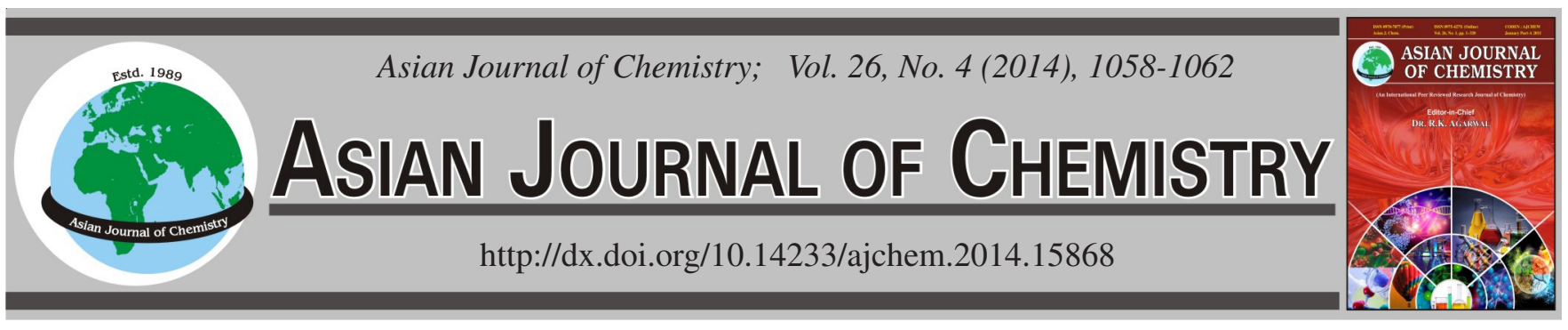

\title{
Desulfurization Activity of Cobalt-Blended into Activated Carbon by One-step Activation Method
}

\author{
Tian Huang ${ }^{1}$, Ye Li $^{1}$, JiaXiu Guo ${ }^{1,2}$, Lu Fan ${ }^{1}$ and Wenju Jiang ${ }^{1,2 *}$
}

${ }^{1}$ College of Architecture and Environment, Sichuan University, Chengdu 610065, P.R. China

${ }^{2}$ National Engineering Research Center for Flue Gas Desulfurization, Chengdu 610065, P.R. China

*Corresponding author: Fax: +86 28 85405613; Tel: +86 28 85403016; E-mail: wenjujiang@ @scu.edu.cn

Received: 5 June 2013;

Accepted: 12 September 2013;

Published online: 15 February 2014;

AJC-14699

\begin{abstract}
Activated carbon was prepared from walnut shell and blended with $\mathrm{Co}_{2} \mathrm{O}_{3}$ powder by one-step activation method. Better development of texture properties on activated carbon was observed by scanning electron microscopy. $\mathrm{N}_{2}$ adsorption-desorption confirmed that the surface area and micro pores volume increased $45 \%$ and $34.2 \%$ after cobalt addition, respectively, compared to blank samples. The results of Fourier-transform infrared spectra indicated that cobalt oxide improved the formation of basic functional groups $(\mathrm{C}=\mathrm{O})$ which would considerably affect the adsorption capability. The surface chemical properties of the activation samples were characterized by energy dispersive spectrum, X-ray diffraction and X-ray photoelectron spectra. Results showed that $\mathrm{Co}$ and $\mathrm{CoO}$ co-existed on activated carbon after activation. The desulfurization capacity of activated carbon-Co5 was $191.7 \mathrm{mg} / \mathrm{g}$ and $49.4 \%$ higher than activated carbon.
\end{abstract}

Keywords: Activated carbon, Cobalt, Blend, Physicochemical properties, Desulfurization activity.

\section{INTRODUCTION}

Sulfur dioxide emitted from the combustion of fossil fuels has been regulated strictly due to its connection with the formation of acid rain, urban smog and health hazards. Recently, a variety of flue gas desulfurization (FGD) technologies have been developed to control the emission of $\mathrm{SO}_{2}$. Among which adsorption desulfurization attract worldwide interest because of its simple process and higher desulfurization efficiency. Many adsorbents have been studied for flue gas desulfurization, such as activated coke ${ }^{1-4}$, metal supported porous materials ${ }^{5}$, activated carbon fiber $(\mathrm{ACF})^{6-8}$, activated carbon ${ }^{5,9,10}$ and zeolite ${ }^{11}$. Activated carbon has been demonstrated to be one of the most effective adsorbents because of its extensive surface area, multipore structure and various surface chemical groups. Nevertheless, the cost can be very expensive when activated carbon is used for flue gas desulfurization, due to the low sulfur capacity of normal activated carbon. Therefore, proper modification for activated carbon is needed to improve its affinity with $\mathrm{SO}_{2}$.

Desulfurization capacity of activated carbon depends on its porosity, surface chemistry and inorganic composition. These factors can be regulated by adding transition metals to improve the desulfurization activity of activated carbon, such as $\mathrm{Fe}^{12}, \mathrm{Ni}^{13}, \mathrm{Mn}^{14,15}, \mathrm{Co}^{16,17}, \mathrm{Cu}^{5}$ and $\mathrm{V}^{4}$. The enhancement of adsorption capacity on $\mathrm{SO}_{2}$ is related with kind of metals and its chemical forms and position in carbon. Some investigators have pointed out that cobalt as a catalyst for activated carbon modification is quite effective and shows the best activity for removal of $\mathrm{SO}_{2}{ }^{18,19}$. The location of metals in carbon depends on the loading methods. Both impregnation and blending method are commonly used for loading metal onto activated carbon. The metal oxides are always located on the surface of activated carbon by impregnation method, but by blending method, the metal oxides are distributed throughout the activated carbon matrix ${ }^{19}$. It is well known that the reaction between metal oxides and carbon during activation process helps the development of texture structure. Therefore, with blending method, it is possible that the evenly distribution of metal oxides in activated carbon is conducive to the production of porosity and improve the desulfurization activity of activated carbon. In this study, walnut shell was carbonized firstly to prepare char, which were then blended with $\mathrm{Co}_{2} \mathrm{O}_{3}$ powder and formed column mixture by extrusion molding. This mixture was consequently activated at $1148 \mathrm{~K} . \mathrm{Co}_{2} \mathrm{O}_{3}$ could be self-assembled on the formed column activated carbon by the one-step direct pyrolysis method to form the cobalt oxide/carbon.

The aim of this paper is to find out the effect of the onestep activation method on the physicochemical properties of activated carbon and to study the role of $\mathrm{Co}_{2} \mathrm{O}_{3}$ in activated carbon or the sulfur dioxide adsorption performance. The surface physical and chemical properties of modified activated carbon were characterized and analyzed. The sulfur dioxide adsorption capacity of the sample was investigated. Furthermore, the possible $\mathrm{SO}_{2}$ adsorption mechanism was also discussed. 


\section{EXPERIMENTAL}

Preparation of activated carbon samples: Walnut shell, from Sichuan province, P.R. China, was used as the raw material. Elemental analysis showed that the walnut shell mainly consisted of C 48.99 wt. \%, H 5.74 wt. \%, and N 0.24 wt. \%.

Firstly, walnut shells presented as particles ranging in $0.14-$ $0.28 \mathrm{~mm}$ by crushed and sieved. Then they were carbonized in an electric furnace (SX2-8-10P, Chengdu, China) at $773 \mathrm{~K}$ for $1 \mathrm{~h}$ at the heating rate of $5^{\circ} \mathrm{C} / \mathrm{min}$ under nitrogen atmosphere. Subsequently, the char powder sieved with 200-mesh screen was mixed with $\mathrm{Co}_{2} \mathrm{O}_{3}$ by blending for $0.5 \mathrm{~h}$. The mixture was stirred thoroughly with binder in kneading machine and molded under $4 \mathrm{MPa}$ in a vacuum extruder to form a column with diameter of $3 \mathrm{~mm}$. Finally, the mixture was activated in the furnace at $1148 \mathrm{~K}$ for $2 \mathrm{~h}$ under $\mathrm{CO}_{2}$ atmosphere $(1000$ $\mathrm{mL} / \mathrm{min}$ ). The prepared activated carbons were named as $\mathrm{AC}$ and the sample containing $\mathrm{Co}_{2} \mathrm{O}_{3}$ was labeled as AC-Cox ( $\mathrm{x}=$ 2, 5, 7 and $10 \%$ ).

Characterization of the activated carbon: Iodine value was measured by China National Standards (GB/T12496.101999) to assess the adsorption capability of the prepared activated carbons. Themorphologies of the samples was obtained with scanning electron microscopy (SEM) using JSM7500F scanning electron microscopy (JEOL) . The main element contents were carried out using energy dispersive spectrometer (EDS) with X-Max 51-XMX0019 instrument (Oxford Instruments) and scanning electron microscopy. BET surface and pore volume were measured on Quadrasorb 2 SI-MP-20 (UK Malvern Instruments Co. Ltd.) using nitrogen adsorption at $77 \mathrm{~K}$. The surface chemical properties of the samples was analyzed by $\mathrm{X}$-ray diffraction (XRD) and X-ray photoelectron spectra (XPS). Detailed analysis was described as follows: XRD patterns were obtained with an X-Pert PRO MPD diffractometer at $30 \mathrm{kV}$ and $20 \mathrm{~mA}$ employing $\mathrm{CuK}_{\alpha}$ radiation and step-scanning over $2 \theta$ range $10-80^{\circ}$. XPS analysis was applied to determine the surface chemical composition and functional groups, using a XSAM 800 spectrometer (KRATOS). Functional groups were discussed by Fourier transforms infrared spectroscopy (FTIR that Bruker Tensor27 spectrometer in the range of $4000-500 \mathrm{~cm}^{-1}$ on sample pellets).

Desulfurization experiment: Desulfurization experiments were carried out in a fixed-bed reactor system. 2000 ppm SO mixed with 9 vol. $\% \mathrm{O}_{2}, 10$ vol. $\%$ water vapor and balance $\mathrm{N}_{2}$ flow through the columnar reactor $(\varnothing 18 \mathrm{~mm} \times 300 \mathrm{~mm})$ which was filled with $15 \mathrm{~g}$ of samples at $600 \mathrm{~h}^{-1}, 353 \mathrm{~K}$. The $\mathrm{SO}_{2}$ concentration was monitored by Gas analyzer (Gasboard3000). The test was stopped at the breakthrough concentration of $1500 \mathrm{ppm}$. Use the curves of sulfur capacity and of $\mathrm{SO}_{2}$ concentration to calculate the capability of $\mathrm{SO}_{2}$ adsorption.

\section{RESULTS AND DISCUSSION}

Optimization of preparation condition: The different amount of $\mathrm{Co}_{2} \mathrm{O}_{3}$ was added to prepare activated carbons to evaluate the performance of samples. The iodine value and yield were chosen as the indicators and the results are showed in Fig. 1. The iodine value curve appears a hump-shape. With the increase of $\mathrm{Co}_{2} \mathrm{O}_{3}$ loading amount, the iodine value increase firstly and then decrease due to the pores blockage caused by

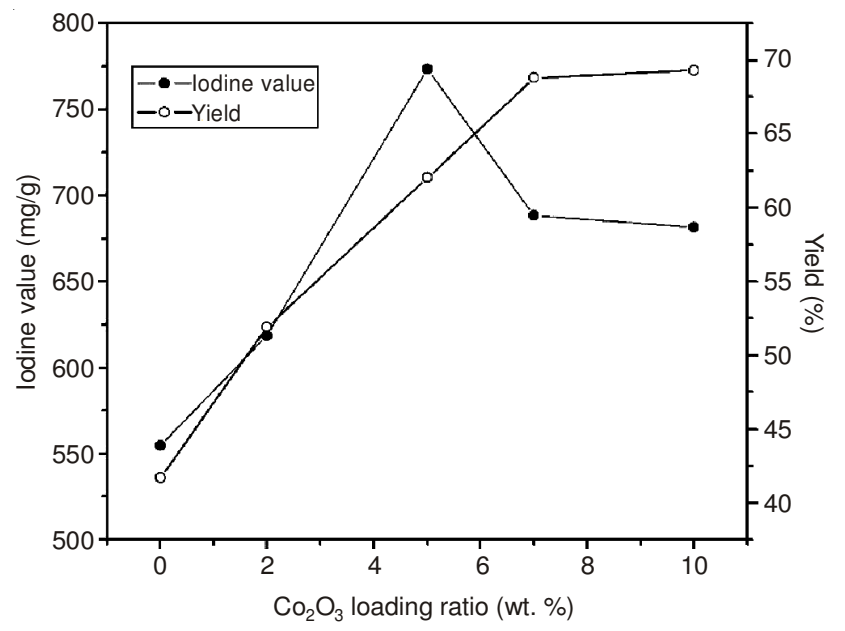

Fig. 1. Effect of loading amount of $\mathrm{Co}_{2} \mathrm{O}_{3}$ on the iodine value and yield of carbon adsorbents

the excess $\mathrm{Co}_{2} \mathrm{O}_{3}$ addition. The highest iodine value is 773.22 $\mathrm{mg} / \mathrm{g}$ when the loading amount is $5 \%$. Meanwhile, with the increase of loading amount, the yield of activated carbon increases continually. In view of the iodine value and the yield, 5 wt. \% loading amount of $\mathrm{Co}_{2} \mathrm{O}_{3}$ was selected for modified activated carbon in the following studies.

\section{Characterization of prepared samples}

Physical properties: SEM technique was employed to observe the surface morphology of $\mathrm{Co}_{2} \mathrm{O}_{3} /$ carbon before and after activation. The results are presented in Fig. 2. The carbon has rough areas with irregular macro pore before activation. After activation, the surface of AC-Co5 has more folds and well pore structure. There are noticeable scattering of cobalt compounds particles on the surface of $\mathrm{Co}_{2} \mathrm{O}_{3}$ /carbon and some are trapped into the pores, indicating that the cobalt oxide particles are well assimilated in the carbon samples.

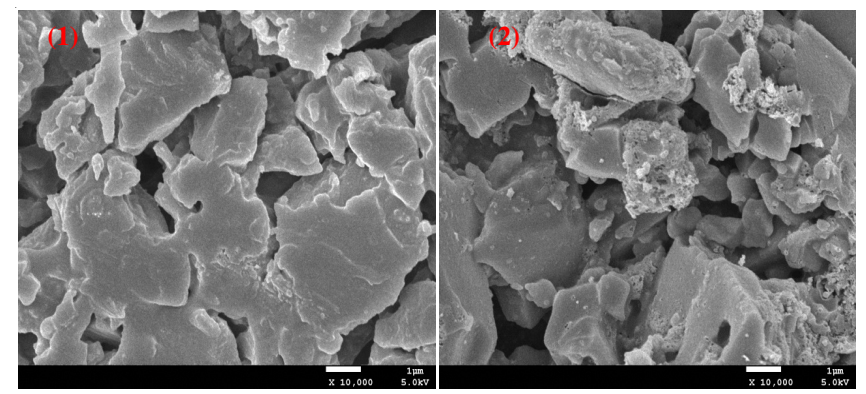

Fig. 2. SEM photographs of AC-Co5 (1) before activation and (2) after activation

The nitrogen adsorption and desorption isotherm for sample AC-Co5 is exhibited in Fig. 3. The adsorption and desorption branches are increased with the increase of relative pressure at first and then became horizontal and parallel to each other over a wide range of relative pressure. This represents type 1 isotherm, which is characteristic of mircroporous materials. Furhermore, the surface area and micropore volume of activated carbon-Co5 increase $45 \%$ and $34.2 \%$, respectively, compared to activated carbon. This is caused by the reaction of metal oxides and carbon substrate during carbon gasification process. It is known that larger surface area and 


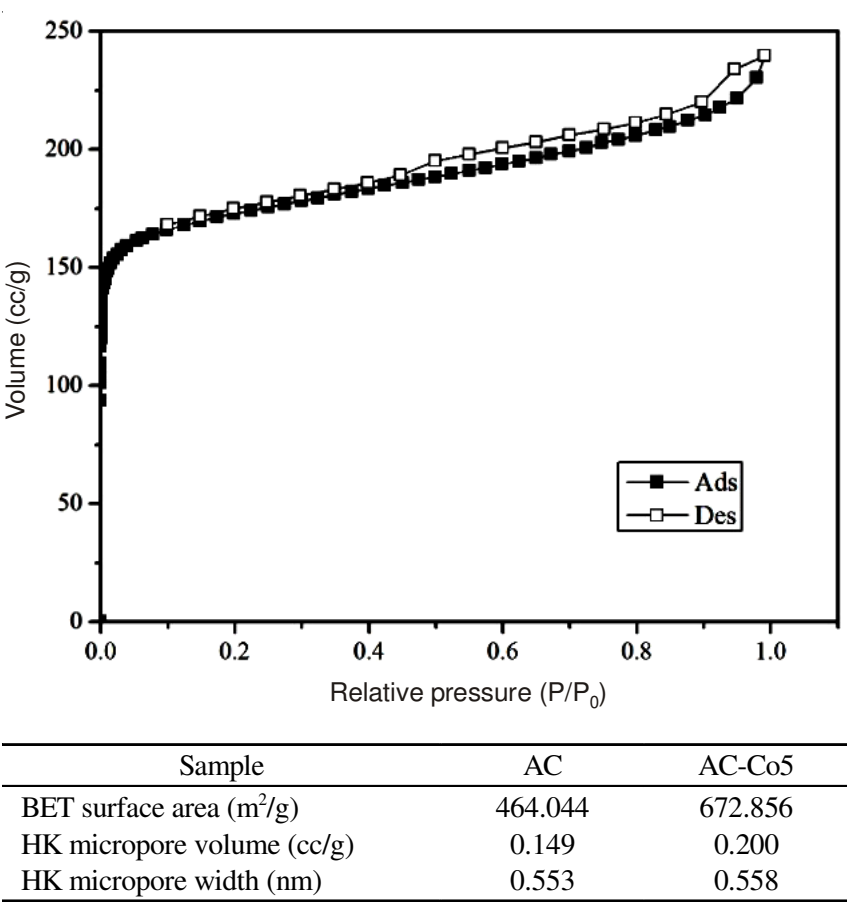

Fig. 3. The nitrogen adsorption and desorption isotherms of activated carbon-Co5 (above) and structure parameters of activated carbon and activated carbon-Co5 adsorbent (below)

pore volume, especially micro pore volume, are beneficial for removal of $\mathrm{SO}_{2}$. The former favors the dispersion of active ingredient and the latter helps the diffusion of reactive molecules. Therefore, it is reasonable to deduce that activated carbon-Co5 would perform well in desulfurization experiment due to their better development in texture properties.

Chemical properties: Energy dispersive spectra of ACCo5 before and after activation are shown in Fig. 4. As seen the spectra showed thepresence of cobalt, oxygen and carbon. The characteristic $\mathrm{K} \alpha$ and $\mathrm{K} \beta$ peaks of cobalt are obtained at 6.93 and $7.65 \mathrm{keV}$, respectively ${ }^{16}$. The carbon content is slight decrease after activation but it is still over $85 \%$. The meanwhile, the $\mathrm{O}$ content is decreased and Co content is increased obviously after the activation with $\mathrm{Co}_{2} \mathrm{O}_{3}$. This occurred because of the reaction between $\mathrm{Co}_{2} \mathrm{O}_{3}$ and carbon during activation process, which led to the consumption of $\mathrm{C}$ and $\mathrm{O}$ in the form $\mathrm{CO}$ or $\mathrm{CO}_{2}$. It is speculated that the cobalt oxide plays an important role to accelerate the chemical changes in the material.

The chemical constitution of the AC-Co5 was examined by XRD and XPS. The results are showed in Figs. 5 and 6. Broad peaks which presented at $2 \theta=24^{\circ}$ and $44^{\circ}$ prove the existence of amorphous carbon structure (Fig. 5(1)). Peaks at $2 \theta=26.6^{\circ}$ and $50.1^{\circ}$ are sharp and minor, corresponding to $\mathrm{SiO}_{2}{ }^{16,17}$. And peaks of metallic $\mathrm{Co}$ are observed at $44.8^{\circ}, 51.7^{\circ}$ and $76.3^{\circ}$, indicating that $\mathrm{Co}_{2} \mathrm{O}_{3}$ have been reduced during carbon activation. According to XPS spectrum (Fig. 6(1)), the Co 2 p3/2 region consists of only one peak at $780.7 \mathrm{eV}$ is observed ${ }^{20}$ due to $\mathrm{Co}^{2+}$, reported to have $\mathrm{BE}$ values between 779 and $781 \mathrm{eV}$. XPS only detect the depth of surface at $2 \mathrm{~nm}$, explaining the absence of Co metal species in form of metallic. Trace amounts and highly dispersed Co metal oxides which covered the surface of the sample caused the Co metal in form
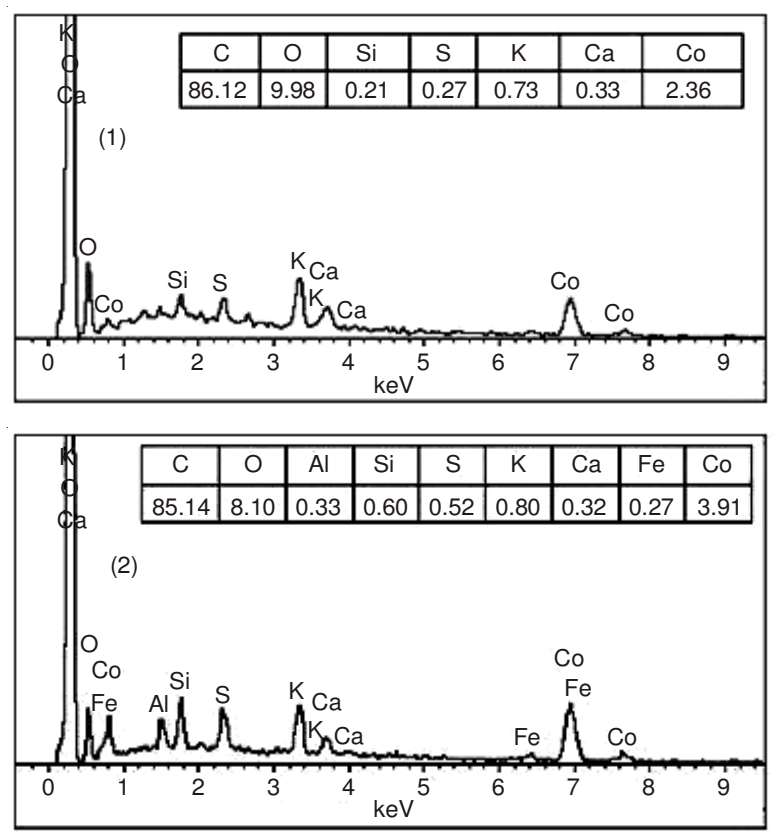

Fig. 4. EDS spectra of AC-Co5 (1) before activation and (2) after activation

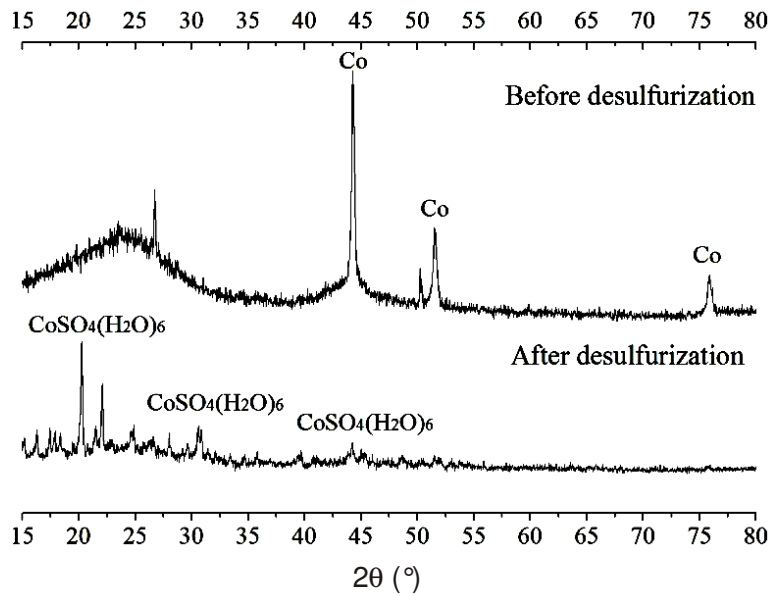

Fig. 5. XRD patterns of AC-Co5 after activation(1) before desulfurization and (2)after desulfurization

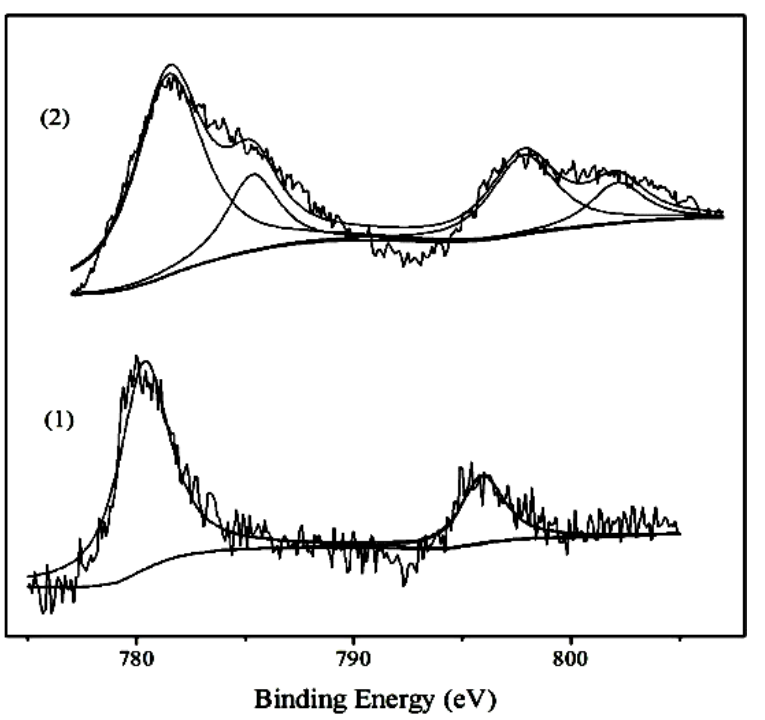

Fig. 6. XPS metal spectra of AC-Co5 (1) after activation (before desulfurization) and (2) after desulfurization 
of metallic over the limit of XPS test so that it is unexposed and undetectable. Based on the result obtained from these two analytical methods, it can be concluded that the chemical valence of $\mathrm{Co}_{2} \mathrm{O}_{3}$ is reduced to $\mathrm{CoO}$ and $\mathrm{Co}$ after activation. This occurred during activation process when high temperature $1148 \mathrm{~K}$ was employed, in which condition added metal oxides decomposed and then may be reduced by reaction with carbon substrate to a lower and more stable oxidation states ${ }^{21}$.

The FTIR of AC-Co5 before and after activation are shown in Fig. 7(1) and 7 (2). These carbons show similar FTIR spectra, suggesting that they have similar functional groups on the surface. Their intensities and slightly shift indicates slight differences in wavenumbers, inspecting small difference in the surface chemistry ${ }^{22}$. The broad band at $3400 \mathrm{~cm}^{-1}$ are observed which is attributed to the presence of $\mathrm{O}-\mathrm{H}$ stretching vibration. Hydrogen bonding made it become the mode of hydroxyl functional groups ${ }^{23} . \mathrm{C}=\mathrm{O}$ stretching vibration which presented as the band at $1630 \mathrm{~cm}^{-1}$ belonging to different functional groups, including quinones, lactones, aldehydes and ketones ${ }^{24}$. Between 1300 and $900 \mathrm{~cm}^{-1}$ can be identified as the C-O vibration. The intense band at around 1150,1100 and $1050 \mathrm{~cm}^{-1}$ is probably assigned to $\mathrm{C}-\mathrm{O}$ vibrations in the structure of ether, the primary and secondary $\mathrm{C}-\mathrm{OH}$, respectively ${ }^{20}$. After activation, the band at $3400 \mathrm{~cm}^{-1}$ is much less pronounced, corresponding to gasification of $\mathrm{H}_{2} \mathrm{O}$ when $1148 \mathrm{~K}$ was employed during activation process. Enhancement of $\mathrm{C}=\mathrm{O}\left(1630 \mathrm{~cm}^{-1}\right)$ is a symbol of carbonyl carbon, indicating alkaline oxygen-containing function groups increased and more alkaline delocalized $\pi$ electrons formed. This is caused by the reaction between cobalt oxides and the carbons. $\mathrm{C}=\mathrm{O}$ is conducive to the adsorption of $\mathrm{SO}_{2}{ }^{25,26}$. However, the slight increment of $\mathrm{C}-\mathrm{O}$, which could be attributed to the transformation of inorganic compounds, is unfavorable for adsorption of $\mathrm{SO}_{2}{ }^{27}$. Furthermore, the aromatic hydrogen (band at 700 and $900 \mathrm{~cm}^{-1}$ ) observed for carbon sample before activation disappeared after reaction with $\mathrm{CO}_{2}$ under high temperature during activation process.

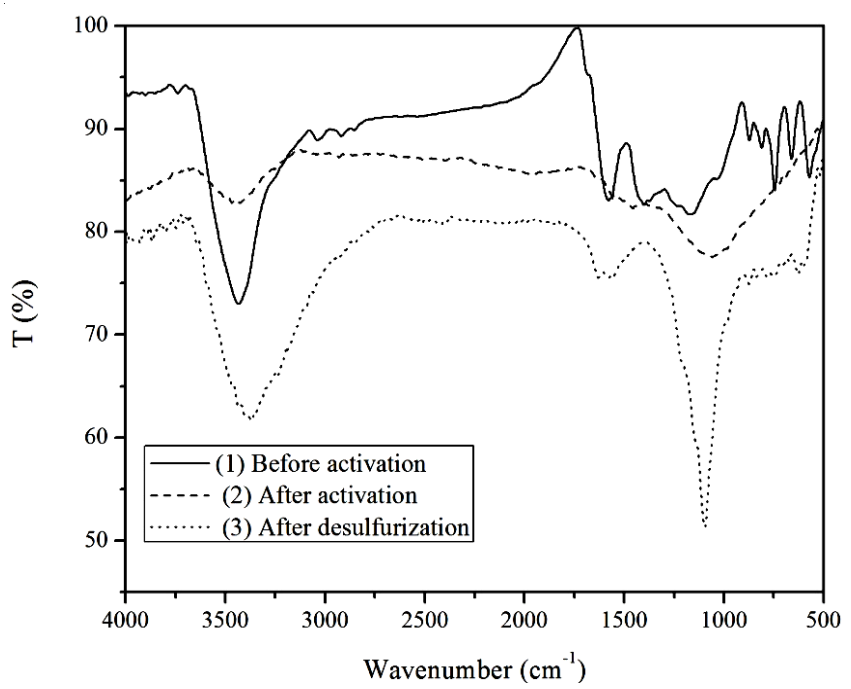

Fig. 7. Fourier-transform infrared spectra of AC-Co5 (1) before activation, (2) after activation and (3) after desulfurization

Adsorption performance of $\mathbf{S O}_{2}$ : The breakthrough curves of AC and AC-Co5 are presented in Fig. 8. AC-Co5 exhibits better performance in $\mathrm{SO}_{2}$ adsorption experiment since it has kept $100 \%$ of $\mathrm{SO}_{2}$ removal efficiency for longer time than that of AC. AC-Co5 kept $100 \%$ of $\mathrm{SO}_{2}$ removal for more than $20 \mathrm{~h}$, while only $10.5 \mathrm{~h}$ for AC. The breakthrough capacity of AC-Co5 is $191.7 \mathrm{mg} / \mathrm{g}$, which is $49.4 \%$ higher than that of $\mathrm{AC}(128.3 \mathrm{mg} / \mathrm{g})$. The breakthrough time of AC-Co5 is $41.5 \mathrm{~h}$, which is $17 \mathrm{~h}$ longer than $\mathrm{AC}(24.5 \mathrm{~h})$.

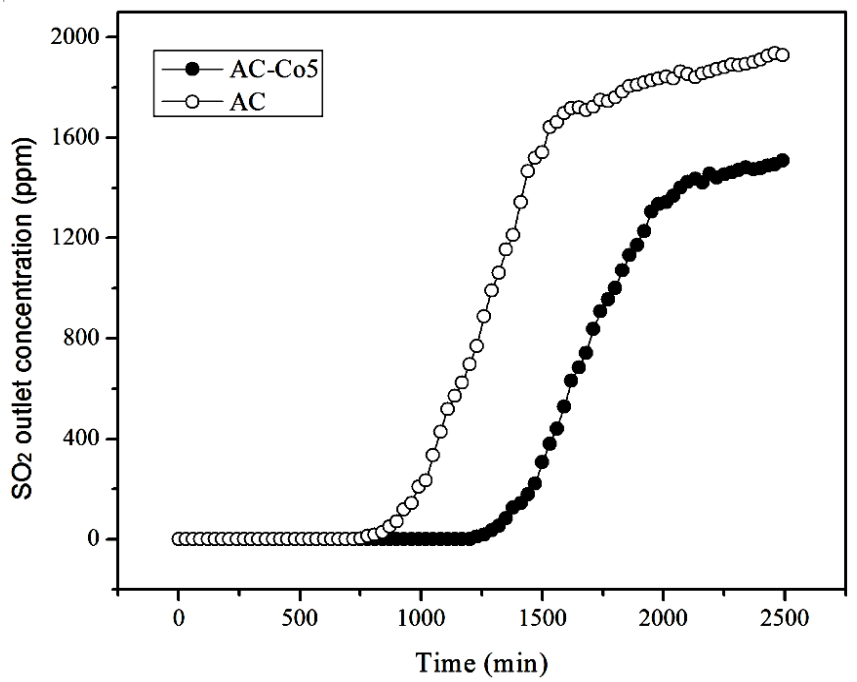

Fig. 8. The breakthrough curves of AC and AC-Co5

The remarkable desulfurization activity enhancement of AC-Co5 is due to its extensive surface area, multi-pore structure, various surface functional groups and the catalytic activity of metal specie on the carbon surface. As mentioned before, activated carbon developed better texture properties after $5 \mathrm{wt}$. $\% \mathrm{Co}_{2} \mathrm{O}_{3}$ addition. This has positive effect on $\mathrm{SO}_{2}$ removal by activated carbon, since higher surface area favors the dispersion of the active ingredient and larger micro pore volume is related to the diffusion of reactive molecules. On the other hand, the basic oxygenate functional groups formed on the activated carbon surface after activation is also beneficial for the desulfurization process. Furthermore, the catalytic activities of metal species contributed to the better desulfurization performance presented by $\mathrm{Co}_{2} \mathrm{O}_{3}$ modified activated carbon. The oxidation state of $\mathrm{Co}_{2} \mathrm{O}_{3}$ was reduced to $\mathrm{Co}^{0}$ and $\mathrm{Co}^{2+}$ during carbon activation (Fig. 5(1) and 6(1)). With the participation of $\mathrm{O}_{2}$ during desulfurization process, Co metal species with reduced state or intermediate state would be gradually oxidized to active $\mathrm{Co}_{2} \mathrm{O}_{3}$ which have much higher catalytic activity than normal $\mathrm{Co}_{2} \mathrm{O}_{3}$. Sulfur dioxide then oxidized to $\mathrm{SO}_{3}$ while active $\mathrm{Co}_{2} \mathrm{O}_{3}$ involved during desulfurization system. At the same time, active $\mathrm{Co}_{2} \mathrm{O}_{3}$ converted reduced into intermediate state $\left(\mathrm{Co}^{2+}\right)$. This process was followed by $\mathrm{H}_{2} \mathrm{SO}_{4}$ generation with $\mathrm{H}_{2} \mathrm{O}$. Cobalt metal species with intermediate state $\left(\mathrm{Co}^{2+}\right)$ would be oxidized by $\mathrm{O}_{2}$ in desulfurization system and form active $\mathrm{Co}_{2} \mathrm{O}_{3}$ again $^{28}$. This catalytic activity of modified activated carbon is reported to be the dominate factor that govern its sulfur capacity. Enhancement of $\mathrm{C}=\mathrm{O}\left(1630 \mathrm{~cm}^{-1}\right)$ is conducive to the adsorption of $\mathrm{SO}_{2}$ (Fig. 7(2)).

Surface chemistry changes after desulfurization: In order to explore some surface chemical changes in the desulfurization process, $\mathrm{AC}-\mathrm{Co} 5$ after desulfurization was characterized 
by XRD, XPS and FTIR. In Fig. 6(2), after reacted with $\mathrm{SO}_{2}$, the binding energies for Co $2 \mathrm{p}_{3 / 2}$ is found at $783.3 \mathrm{eV}$ and $787.8 \mathrm{eV}$, which corresponding to cobalt(II) and cobalt(II) satellite ions ${ }^{29,30}$. According to Klinik and Grzybek ${ }^{31}$, the higher binding energy of $\mathrm{Co} 2 \mathrm{p}_{3 / 2}$ after removal of $\mathrm{SO}_{2}$ may indicates that the active material is present as $\mathrm{CoSO}_{4}$. This result is also presented by XRD pattern (Fig. 5(2)).

In Fig. 7(3), the peak intensity at $1065 \mathrm{~cm}^{-1}$ is obviously enhanced due to the formation of $\mathrm{C}-\mathrm{O}$ structures after $\mathrm{SO}_{2}$ adsorption, indicating the catalysis activity of cobalt ${ }^{32}$. The possible desulfurization mechanism could be described as following formula. Moreover, after $\mathrm{SO}_{2}$ adsorption, the peak of $3430 \mathrm{~cm}^{-1}$ was much less pronounced, suggesting the reaction between $\mathrm{OH}$ groups and sulfur oxide.

$$
\begin{aligned}
& \mathrm{Co}+\mathrm{C} \rightarrow \mathrm{Co}-\mathrm{C} \\
& \mathrm{Co}-\mathrm{C}+\mathrm{O}_{2} \rightarrow \mathrm{Co}-\mathrm{O}+\mathrm{C}-\mathrm{O} \\
& \mathrm{Co}-\mathrm{O}+\mathrm{SO}_{2} \rightarrow \mathrm{CoSO} \\
& \mathrm{CoSO}_{3}+\mathrm{H}_{2} \mathrm{O} \rightarrow \mathrm{Co}_{2} \mathrm{H}_{2} \mathrm{SO}_{4}
\end{aligned}
$$

Based on the above analysis, some surface chemical reaction actually took place in the desulfurization process, which is one of the factors of the degradation of desulfurization performance.

\section{Conclusion}

The cobalt oxide/carbon is prepared by using walnut shells as precursor and cobalt oxide as activating agent. The cobalt oxide plays an important role on the formation of porous structure and functional groups. Chemical states of Co on activated carbon were reduced during activation process and presented as $\mathrm{Co}^{0}$ and $\mathrm{Co}^{2+}$. The desulfurization activity enhancement of cobalt oxide/carbon adsorbents is mainly because of the existence of Co active species.

\section{ACKNOWLEDGEMENTS}

This project is financially supported by the National Natural Science Foundation of China (Project No. 51078245).

\section{REFERENCES}

1. S. Ogriseck and G.P.G. Vanegas, Chem. Eng. J., 160, 641 (2010).

2. X.L. Zhang, Y. Zhang, F.S. Ding, Q.J. Huang and Y. Li, Min. Sci. Technol., 19, 769 (2009).
3. J.J. Li, N. Kobayashi and Y.Q. Hu, Chem. Eng. Process., 47, 118 (2008).

4. Y. Xiao, Q.Y. Liu, Z.Y. Liu, Z.G. Huang, Y.X. Guo and J.L. Yang, Appl. Catal. B, 82, 114 (2008).

5. H.H. Tseng, M.Y. Wey and C.H. Fu, Carbon, 41, 139 (2003).

6. E. Raymundo-Piñero, D. Cazorla-Amorós and A. Linares-Solano, Carbon, 39, 231 (2001).

7. E. Raymundo-Piñero, D. Cazorla-Amorós and A. Linares-Solano, Carbon, 41, 1925 (2003).

8. J.Y. Wang, F.Y. Zhao, Y.Q. Hu, R.H. Zhao and R.J. Liu, Chin. J. Chem. Eng., 14, 478 (2006).

9. P. Davini, Carbon, 40, 729 (2002).

10. P. Davini, Carbon, 39, 2173 (2001).

11. J. Morency, Filtr.Sep., 39, 24 (2002).

12. J. Akhtar, N.A.S. Amin and A. Aris, Chem. Eng. J., 170, 136 (2011).

13. C.Z. Wu, M. Song, B.S. Jin, Y.M. Wu, Z.P. Zhong and Y.J. Huang, J. Anal. Appl. Pyrolysis, 99, 137 (2013).

14. A. Uçer, A. Uyanik and S.F. Aygün, Sep. Purif. Technol., 47, 113 (2006).

15. J. Ma, M.H. Sui, Z.L. Chen and L.N. Wang, Catal. Rev., 26, 3 (2004).

16. P.R. Shukla, S.B. Wang, H.Q. Sun, H.M. Ang and M. Tadé, Appl. Catal. $B, \mathbf{1 0 0}, 529$ (2010).

17. K.H. Chan and W. Chu, Water Res., 43, 2513 (2009).

18. J.Y. Wang, F.Y. Zhao, Y.Q. Hu, R.H. Zhao and R.J. Liu, Chin. J. Chem. Eng., 14, 478 (2006).

19. X. Gao, S.J. Liu, Y. Zhang, Z.Y. Luo and K.F. Cen, J. Hazard. Mater., 188, 58 (2011).

20. J.L. Gautier, E. Rios, M. Gracia, J.F. Marco and J.R. Gancedo, Thin Solid Films, 311, 51 (1997).

21. S.A. Carabineiro, D.W. McKee and I.F. Silva, Carbon, 39, 451 (2001).

22. X.Q. Wang and U.S. Ozkan, J. Phys. Chem. B, 109, 1882 (2005).

23. Z.G. Yin, N.F. Chen, F. Yang, S.L. Song, C.L. Chai, J. Zhong, H. Qian and K. Ibrahim, Solid State Commun., 135, 430 (2005).

24. A. Urbano, S.C. deCastro, R. Landers, J. Morais, A.D. Siervo, A. Gorenstein, M.H. Tabacniks and M.C.A. Fantini, J. Power Sources, 97-98, 328 (2001).

25. B.R. Puri and R.C. Bansal, Carbon, 1, 451 (1964).

26. A.A. Lizzio and J.A. DeBarr, Fuel, 75, 1515 (1996).

27. K.X. Li, L.C. Ling, C.X. Lu, Z.Y. Liu, L. Liu and I. Mochida, Fuel Process. Technol., 70, 151 (2001).

28. H. Watanabe, R. Kurose and S. Komori, J. Environ. Eng., 4, 1 (2009).

29. N. Patel, G. Guella, A. Kale, A. Miotello, B. Patton, C. Zanchetta, L. Mirenghi and P. Rotolo, Appl. Catal. A, 323, 18 (2007).

30. E. Szlyk, S. Biniak, A. Surdykowski, I. Lakomska, M. Barwiolek and E. Larsen, Transition Metal Chem., 27, 501 (2002).

31. J. Klinik and T. Grzybek, Fuel, 71, 1303 (1992).

32. C. Moreno-Castilla, F.J. Maldonado-Hódar and A.F. Pérez-Cadenas, Langmuir, 19, 5650 (2003). 